\title{
Spatial memory in rufous hummingbirds (Selasphorus rufus): A field test
}

\author{
S. D. HEALY \\ University of Oxford, Oxford, England \\ and \\ T. A. HURLY \\ University of Lethbridge, Lethbridge, Alberta, Canada
}

\begin{abstract}
The spatial memory abilities of free-ranging rufous hummingbirds were tested in an "open-field" analogue of a radial maze. Eight artificial "flowers" filled with sucrose solution and arranged in a circle were placed within each bird's feeding territory. The birds were given two types of trial: in "free" trials, birds could choose which four of eight flowers to feed from before leaving the array; in "forced" trials, the experimenter presented birds with four flowers. Memory performance was assessed by observing the ability of the birds to avoid the emptied flowers on the return visit. On both types of trials, hummingbirds were able to avoid visiting the previously emptied flowers for retention intervals ranging from a few minutes to over an hour. Demonstration of good memory performance in free-ranging, nondeprived animals has both ethical and logistical implications for future studies on animal memory. In addition, such studies offer an ideal opportunity to test what and how well animals remember in their natural environment.
\end{abstract}

Individuals of many species of hummingbird defend a territory, the size of which is determined by food supply in terms of the number of flowers within the territory or the amount of nectar produced by them (Gass, Angehr, \& Centa, 1976; Kodric-Brown \& Brown, 1978). In the course of a day, a hummingbird will visit hundreds of nectar sources and thus seriously affect the abundance and distribution of food for subsequent foraging bouts. To forage efficiently, a territorial hummingbird should remember the locations of flowers it has depleted and avoid revisiting them until the nectar has been replenished (not less than $4 \mathrm{~h}$; Armstrong, Gass, \& Sutherland, 1987).

The radial-arm maze is a laboratory apparatus frequently used for testing spatial working memory abilities in animals, most commonly rats (e.g., Beatty \& Shavalia, 1980; Olton \& Samuelson, 1976). In 1986, Spetch and Edwards modified the standard arrangement of opentopped tunnels into what they called an open-field feeding environment. In this set-up, the animals were not required to return to a central site but could move directly

We would like to thank Tim Guilford, John Krebs, Gail Michener, Peter Urcuioli, and two anonymous referees for their helpful comments on earlier drafts of this manuscript and John Vokey for statistical advice. S.D.H. was supported by St John's College, Oxford, and T.A.H. was funded by NSERC, Canada. T.A.H. is in the Department of Biological Sciences at Lethbridge. Correspondence concerning this article should be addressed to S. D. Healy, Department of Psychology, University of Newcastle, Newcastle upon Tyne NEl 7RU, England. between feeding sites. Pigeons were tested in two different environments: one involved moving between feeding sites on the ground; the other required the pigeons to fly between the sites. One apparent advantage of this "open-field" radial-arm maze analogue is that the pigeons demonstrated accurate spatial memory within just a few trials. In previous tests with the standard radial maze, pigeons' accuracy was either poor (Bond, Cook, \& Lamb, 1981) or difficult to achieve without extensive training (Roberts \& Van Veldhuizen, 1985). Since Spetch and Edwards' work, several other authors have used an open-field environment to demonstrate accurate spatial memory in various avian species-in corvids (Balda \& Kamil, 1988) and parids (Hilton \& Krebs, 1990), for example.

In the present experiment, we tested the accuracy of spatial memory in hummingbirds using an apparatus that can be described as "open-field" both literally and in its analogy to a radial-arm maze. Artificial flowers containing sucrose solution were presented to rufous hummingbirds (Selasphorus rufus) in their feeding territories at a field site in the eastern Rocky Mountains. In the spring, rufous hummingbirds migrate northward from Mexico to southern Alberta, where they establish feeding territories. These feeding territories consist of over 200 flowers (Armstrong et al., 1987; Paton \& Carpenter, 1984), and the owners vigorously defend them from conspecifics attempting to rob nectar. Because flowers may take some considerable time to replenish (Gass et al., 1976), a hummingbird may follow one or several strategies in order not to revisit recently emptied flowers: visiting flowers in a consistent pattern whereby 
Table 1

Mean Retention Intervals and Intertrial Intervals in Minutes ( \pm Standard Errors) for 6 Hummingbirds Performing Free (Averaged Over Both Blocks) and Forced Trials

\begin{tabular}{|c|c|c|c|c|c|c|c|c|}
\hline \multirow[b]{3}{*}{ Bird } & \multicolumn{4}{|c|}{ Retention Interval } & \multicolumn{4}{|c|}{ Intertrial Interval } \\
\hline & \multicolumn{2}{|c|}{ Free Trials } & \multicolumn{2}{|c|}{ Forced Trials } & \multicolumn{2}{|c|}{ Free Trials } & \multicolumn{2}{|c|}{ Forced Trials } \\
\hline & $M$ & $S E$ & $M$ & $S E$ & $M$ & $S E$ & $M$ & $S E$ \\
\hline$\overline{\text { Female } 1}$ & 4.8 & 1.0 & 13.0 & 4.4 & 79.9 & 9.4 & 204.6 & 129.3 \\
\hline Female 2 & 8.1 & 2.0 & 11.7 & 6.0 & 62.4 & 6.4 & 178.7 & 108.3 \\
\hline Female 3 & 6.5 & 1.2 & 14.5 & 2.3 & 138.1 & 58.8 & 203.6 & 86.3 \\
\hline Male 1 & 5.8 & 2.8 & 7.8 & 2.0 & 295.3 & 136.2 & 72.8 & 5.1 \\
\hline Male 2 & 31.0 & 4.4 & 42.8 & 9.7 & 440.4 & 102.8 & 347.6 & 152.5 \\
\hline Male 3 & 4.3 & 1.7 & 13.3 & 3.8 & 164.1 & 70.9 & 225.3 & 100.9 \\
\hline
\end{tabular}

memory is required only for the pattern and not the flowers themselves ("trap-lining"; Feinsinger, 1978), visiting clumps of flowers and remembering the clump visited but not the individual flowers themselves, and remembering the specific locations of individual flowers. Each of these possible strategies has been discussed previously, and there is support from optimality models and experimental tests for the first two (Davies \& Houston, 1981; Gill \& Wolf, 1977; Kamil, 1978). In the following experiment, the artificial flowers containing sucrose solution served as each "arm" of the open-field radial maze so that we could test whether the birds could remember which individual "flowers" were emptied in a recent foraging bout.

\section{METHOD}

\section{Subjects}

The subjects were 3 adult female and 3 adult male rufous hummingbirds. In order to distinguish individuals, the males were marked with a distinctive daub of paint. Plumage patterns on the throats of the females differed enough so that individuals could be identified without painting.

\section{Experimental site}

The study was conducted in two meadows in a valley $(1,400-\mathrm{m}$ elevation) in the Eastern Rocky Mountains, $20 \mathrm{~km}$ southwest of Beaver Mines, Alberta $\left(49^{\circ} 29^{\prime} \mathrm{N} ; 114^{\circ} 25^{\prime} \mathrm{W}\right)$, where male and female rufous hummingbirds defend feeding territories from May through August. Trials were run between 0630 and $2100 \mathrm{~h}$ Mountain Standard Time during July and August 1992.

\section{Procedure}

Initial training. Artificial feeders containing $16 \%$ sucrose solution were placed at several sites where hummingbirds were observed to be feeding from natural flowers. Within a few hours, a hummingbird began to defend the feeder and the immediate vicinity. If male, this bird was then painted while feeding or, if female, her throat pattern was closely observed as she sat at the feeder. Once the focal bird's domination of the feeder was established, the feeder was lowered from its original height $(1.5-2.5 \mathrm{~m}$ from the ground) to about $60 \mathrm{~cm}$ from the ground. When the bird was using the feeder in its new position, the feeder was replaced with an artificial flower. These flowers consisted of a disk of waxed, colored card (diameter, $5.8 \mathrm{~cm}$ ), the center of which was pierced by a pale orange syringe tip. The syringe tip created a small well (capacity, $120 \mu \mathrm{l}$ ). Each bird tested was presented with flowers of only one color, but the colors differed among birds (orange, blue, red, yellow, purple, or white). The flowers were mounted on $60-\mathrm{cm}$ wooden stakes. During this phase of initial training, the syringe tip was filled with $24 \%$ sucrose solution. The birds learned very quickly to feed from the flowers, usually on their first exposure. After a bird had drained the first flower, it was refilled immediately and two or three more flowers were provided. The number of flowers available was gradually increased to a total of eight. These eight flowers were then arranged roughly in a circle $180 \mathrm{~cm}$ in diameter, with approximately $70 \mathrm{~cm}$ between adjacent flowers. Within the circle and between the flowers, the vegetation was cut down or removed so as not to hinder movement between flowers. Handling time was just a few seconds per flower.

Once a bird had fed from the array of eight flowers three or four times over the course of 3 or $4 \mathrm{~h}$, it was given two training trials. For these trials, $40 \mu \mathrm{l}$ of $24 \%$ sucrose solution was put into all eight flowers and the bird was allowed to empty each of them. The flowers were not refilled. The sequence of visiting flowers was recorded until all eight flowers had been emptied. This was done to ensure that birds were not just visiting a subset of the available flowers. When a bird visited a flower, it would nearly always consume the entire contents. Once the bird had emptied all eight flowers, the flowers were removed, but the wooden stakes remained in place. One hour later, all eight flowers were replaced, and again each contained $40 \mu \mathrm{l}$. These two bouts of emptying all eight flowers were the "training trials." Although all the flowers a bird experienced appeared to be identical (at least to our eyes), we scrambled the location of the individual flowers across trials to control for the possibility that the birds might associate a particular flower with a particular location.

Testing. One hour after the bird had completed the second training trial, the experiment proper began. This consisted of three blocks of trials: a block of "free" trials, a block of "forced" trials, and a second block of "free" trials. Birds were run one at a time, completing all trials, before the next bird was tested. Furthermore, because the maze was put in the focal bird's territory, potential intruders were chased away by the subject under test. Most birds received 8-12 trials in a day, so it required $2-4$ days to complete all trials on each bird.

Table 2

Sex, and the Number of Free and Forced Trials for Each of the Birds

\begin{tabular}{llccc}
\hline & & \multicolumn{2}{c}{ No. Free Trials } & \\
\cline { 2 - 4 } Bird & Sex & Block 1 & Block 2 & No. Forced Trials \\
\hline 1 & female & 6 & 4 & 6 \\
2 & female & 6 & 4 & 6 \\
3 & female & 6 & 5 & 10 \\
4 & male & 6 & - & 6 \\
5 & male & 5 & 4 & 5 \\
6 & male & 6 & 3 & 6 \\
\hline
\end{tabular}


In a "free" trial, the bird was presented with all eight flowers containing $40 \mu \mathrm{l}$ of $24 \%$ sucrose solution. When it had visited four of the flowers, it was interrupted by the experimenter and chased away (Phase 1). On return, the bird was then observed until it had visited the four flowers that still contained sucrose solution (Phase 2). The length of the intervening retention interval was thus determined by the bird and was highly variable (see Table 1). When the bird had emptied all the flowers on its return visit, it flew off, and we removed the flowers (the stakes remained in place). On the average, the birds received $5.8( \pm 0.2 S E)$ trials in the first block of free trials and $3.5( \pm 0.6)$ trials in the second block (see Table 2). The average intertrial interval is shown for each bird in Table 1 . We imposed an intertrial interval of $1 \mathrm{~h}$ but since birds did not necessarily return as soon as we put out the flowers, this was the minimum interval between trials. The number of trials per condition varied among birds, for two reasons: (1) The birds migrate south in early August, so in order to complete the testing of 6 birds, the number of test trials was reduced after the 1 st bird had been tested (Female 3); and (2) 2 subjects were displaced from their feeding territories by other birds, so we could no longer test them.

A "forced" trial was one in which Phase 1 consisted of presenting the bird with only four of the flowers, their locations in the array being randomly chosen with the restriction that no more than two adjacent flowers were presented. The bird left after visiting all four flowers. The experimenter then added the four remaining flowers, each containing $40 \mu \mathrm{l}$ of sucrose solution, so that the array consisted of the four emptied flowers and four full flowers. When the bird returned, it was observed until it had emptied the four flowers containing solution (Phase 2). The birds received an average of $6.5( \pm 0.7)$ forced trials. See Table 1 for the average retention interval and intertrial interval for each bird.

To ensure that birds were not distinguishing between full and empty flowers via visual or olfactory cues, we presented 4 of the birds with two control trials following the experimental trials. On control trials, all eight flowers were presented, with four randomly selected flowers containing solution, and the birds were permitted to visit all eight flowers without interruption. If birds were not able to determine, by sight or by smell, which flowers contained solution, their performance on these trials should have approximated chance levels.

The data collected consisted of the sequence in which the bird visited the flowers in both phases, including revisits; the retention interval, and the intertrial interval.

\section{RESULTS}

Because revisits constituted only $6 \%$ of the total visits within each of the phases, revisits were excluded from the following analyses.

\section{Performance Relative to Chance}

The birds' performances on free trials were assessed by recording their ability to find the second four rewarded flowers upon returning to the maze after being chased away. The accuracy of the first four choices that the birds made in Phase 2 was compared, in a one-sample $t$ test, with chance performance of $50 \%$. (These data were arcsin square root transformed prior to analysis). All tests were two-tailed. Performance was significantly better than chance in both blocks of free trials when the mean performances of all birds were combined [Block 1, $t(5)=4.02, p<.01$; Block $2, t(4)=3.34, p<.025]$. Four of the 6 birds in the first block and 4 of the 5 birds in the second block performed better than chance (Fig-

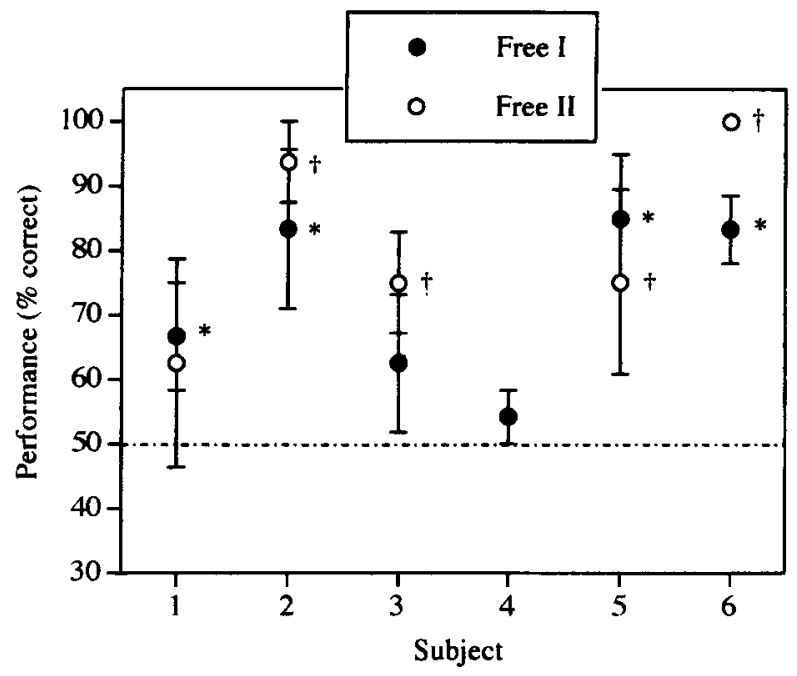

Figure 1. Mean pencent correct performance and standard errors for each bird in the two blocks of free trials. Asterisks denote performances that were significantly different from chance $(p<.05)$ in the first block of free trials (closed circles), and daggers denote performances that were significantly different from chance $(p<.05)$ in the second block of free trials (open circles).

ure 1). When each bird's performance was combined over both blocks of trials, 5 of the 6 birds performed better than chance (Figure 2).

For the forced trials, the birds' abilities to find the second four flowers, as a percentage of the total eight flowers, were also compared with chance $(50 \%)$ performance in one-sample $t$ tests. Performance averaged over subjects was significantly better than chance $[t(5)=$

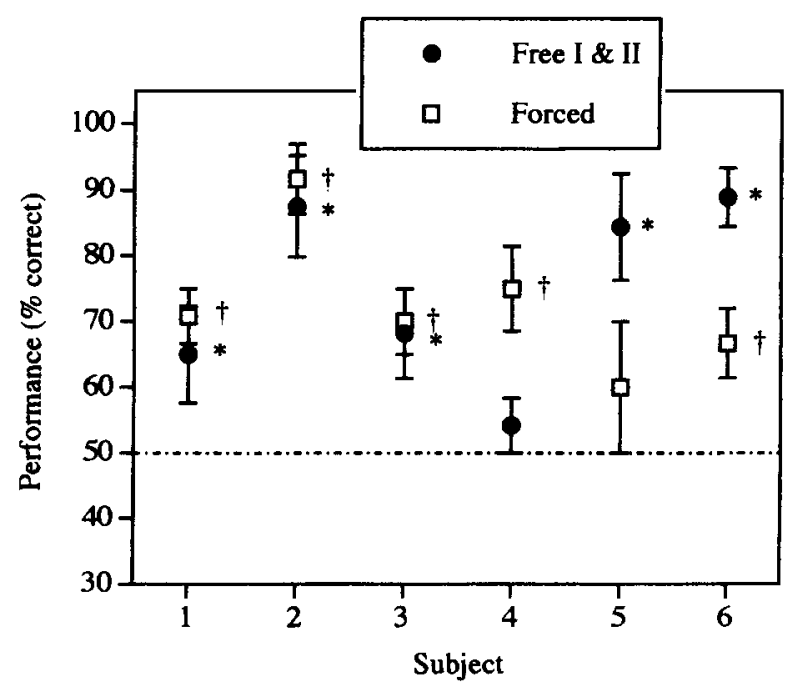

Figure 2. Mean percent correct performance and standard errors for each bird for forced trials (open squares) and for both blocks of free trials combined (closed circles). Asterisks denote performances that were significantly different from chance $(p<.05)$ in the combination of the two blocks of free trials, and daggers denote performances that were significantly different from chance $(p<.05)$ on forced trials. 
$4.39, p<.005$ ], with 5 of the 6 birds performing better than chance (Figure 2).

Another measure of a bird's accuracy was to test whether the bird chose a full flower on its first visit in Phase 2. If the bird was choosing from four full and four empty flowers, the probability of choosing correctly on the first try was .5. One-sample $t$ tests were again used to assess whether or not performance was better than chance. The percentage of correct first visits was combined across birds for each condition. In all cases, birds performed better than chance [Free 1, $t(5)=2.64, p=$ .046 ; Free $2, t(5)=2.97, p=.031$; Free 1 and $2, t(5)=$ $2.97, p=.031$; Forced, $t(5)=2.57, p=.05]$. Thus, as is shown in Figure 3, the birds were able to locate a full flower (and avoid emptied flowers) without having to explore or to remind themselves of the empty flowers.

To assess whether or not nonspatial (e.g., visual or olfactory) cues might account for the birds' accurate performances on the free and forced trials, control trials were run in which only four of the eight flowers were filled with the sucrose solution at the time of the initial visit to the maze. Figure 3 also shows the average accuracy of the birds in finding those four flowers in their first four choices of the control trials and in selecting any one of the four filled flowers on their very first choice. By both measures, birds performed at chance on these trials.

There were not sufficient data to make a detailed assessment of the way in which the birds moved around the array in Phase 1 of free trials, but it was possible to determine how frequently the birds simply moved from one

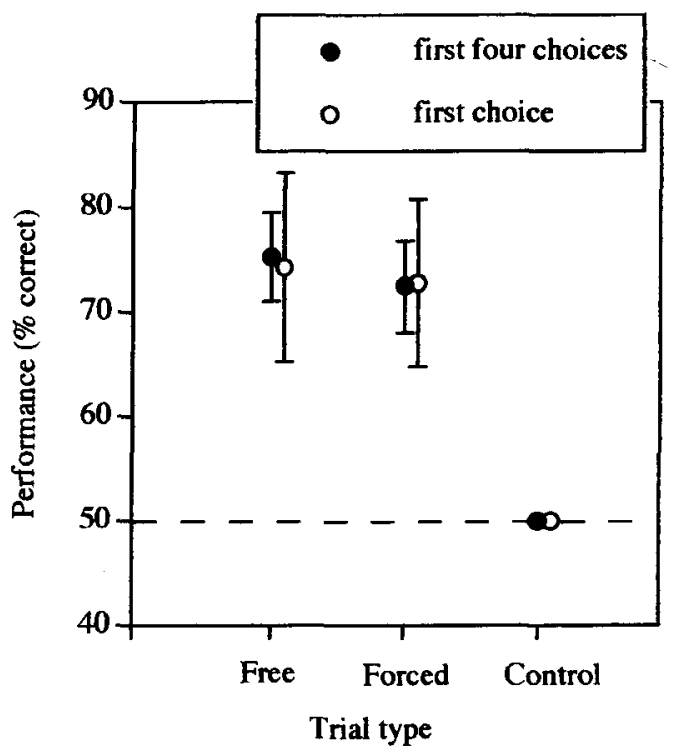

Figure 3. Average percent correct performance (with standard errors) for first four choices in Phase 2 for each of the trial types, and the average proportion of visits to a full flower on the first visit in Phase 2 (closed circles). The open circles denote performance of the birds as the proportion of trials in which the first visit during Phase 2 was to a full flower (with standard errors). The dashed line denotes chance performance $(50 \%)$.

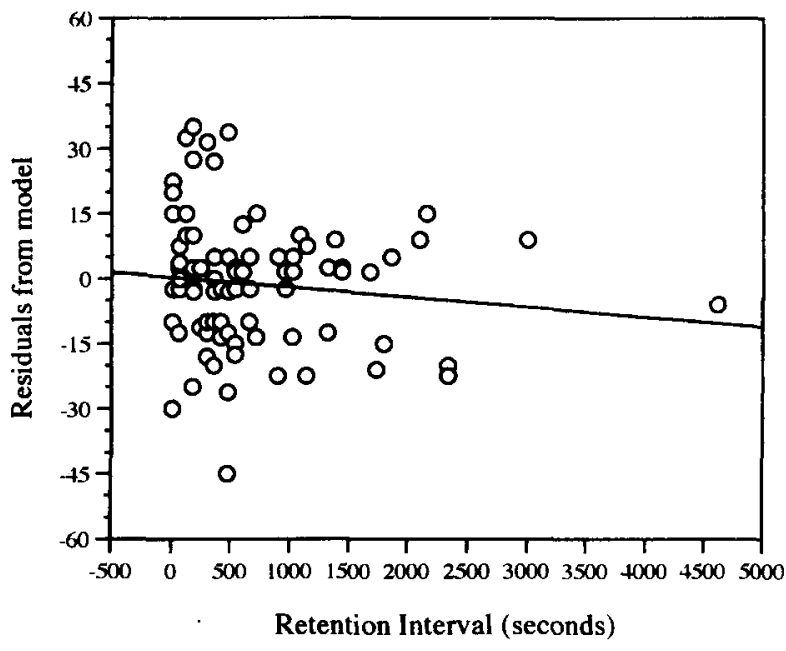

Figure 4. The effect of retention interval (RI) on performance in Phase 2 (all treatments combined). The dependent variable represents residuals from the analysis of variance model accounting for individual, sex, and treatment (see text for additional details). Exclusion of the extreme point on the RI axis had little effect on the results. The slope of the regression line is not significantly different from zero.

flower to its next nearest neighbor. The proportion of all free trials for which the birds visited four sequential flowers in Phase 1 was $0.51 \pm 0.11$ ( $M$ and $S E$ for all 6 birds). Thus, the birds did not appear to rely solely on a simple sequential search pattern to move among flowers.

\section{Effect of Retention Interval}

To examine the effects of individual, sex, treatment (free or forced trials), and retention interval (RI) on performance, we performed an analysis of variance (ANOVA). Individuals were nested within sex, crossing treatment (all fixed factors). The 94 observations nested within individual and treatment acted as the random variate, and $\mathrm{RI}$ was treated as a continuous variable. $\mathrm{Be}-$ cause the number of observations for individual and treatment were not equal, we used Type III sums of squares. The only significant source of variation was individual $[F(4,76)=5.599, p=.0005]$. No significant effects were attributed to the other main factors or to their interactions $(F \mathrm{~s}<1.9, p \mathrm{~s}>.16)$. In short, performance did not differ among free block 1 , forced, and free block 2 treatment conditions.

The ANOVA suggested that performance decreased slightly with RI, but this effect was not statistically significant $[F(1,76)=2.997, p=.088]$, despite the fact that RI ranged from $4 \mathrm{sec}$ to $77 \mathrm{~min}(M=10.63 \mathrm{~min}$; $S E=1.3 \mathrm{~min}$ ). The lack of a significant RI effect can be visualized best by controlling for individual, sex, and treatments in the original ANOVA and plotting residuals from the model against RI (Figure 4).

Since RI was determined by the subjects and not by the experiment, some insights may be gained by treating $\mathrm{RI}$ as a dependent variable rather than an independent variable. In this case, RI varied significantly with treat- 
ment $[F(2,77)=12.951, p=.0001]$ and individual $[F(4,77)=7.587, p=.0001]$, but not with sex or any of the interactions $(F \mathrm{~s}<1.8, p \mathrm{~s}>.1)$. Essentially, the birds exhibited longer retention intervals during forced trials than they did during free trials (see Table 1). It is clear that treatment and RI were confounded in some way, and detailed considerations of retention interval will require further investigation.

\section{DISCUSSION}

In this experiment, an open-field analogue of the radial-arm maze was used to test the spatial memory abilities of rufous hummingbirds. In both free and forced trials, relatively accurate memory was demonstrated over time periods of up to an hour. There seemed to be a slight decline in performance with increasing retention interval, although this result is difficult to interpret because this interval was not controlled by the experimenter, but instead was determined by when subjects returned to the maze for Phase 2. This, in turn, was affected by treatment condition. On free trials, the subjects emptied four of the eight visible flowers and returned fairly quickly after being chased away. On forced trials, however, the subjects were presented with only four flowers during Phase 1, and they left of their own accord. Retention interval was much longer during the latter trials, presumably because the birds perceived that no additional food was immediately available within the array. Thus, reliable conclusions concerning the influence of retention interval on memory performance cannot be drawn from this data set, and the issue must therefore be deferred to a future experiment in which retention interval is manipulated as an independent variable.

Although the radial-arm maze and its analogues have been well used both in testing the spatial memory abilities of intact animals and in demonstrating the effects of various brain lesions and pharmacological treatments, this is the first time, to our knowledge, that it has been used on free-ranging animals. There are drawbacks to testing memory abilities in the field. For example, in our experiment, the bird, not the experimenter, determined both the onset of the experiment and the length of the retention interval. It is also much more difficult in the field to design the radial maze in order to force the subject to the center between choices, as is the standard procedure with rats and as has been done very neatly by Hilton and Krebs (1990) with tits. As with the pigeons of Spetch and Edwards (1986) and the nutcrackers of Balda and Kamil (1988), we allowed the hummingbirds to move directly from site to adjacent site. But in spite of not being able to control the birds' behavior as thoroughly as one could in a laboratory situation, we were still able to assess memory performance.

The hummingbirds that we tested showed good spatial memory on this task over intervals of up to an hour. In the free trials, this performance was not due to the birds' simply moving from one flower to its most immediate neighbor - although this would, in fact, have been the most efficient way to harvest the available food. Performance on forced trials, however, is the real test for memory of specific flowers rather than for particular routes. On forced trials, the hummingbirds were able to remember which flowers to avoid in the second phase just as successfully as they did on free trials. It seems, then, as if the birds remembered which particular flowers they had emptied and not simply the route taken within a clump or patch of flowers.

The ability of hummingbirds to avoid recently visited rewarded sites has been previously demonstrated in the laboratory in a win-shift versus win-stay paradigm. Cole, Hainsworth, Kamil, Mercier, and Wolf (1982) demonstrated a preference for shift learning over stay learning in three species of hummingbird. The retention intervals in Cole et al.'s study were, however, on the order of only a few seconds. Although the birds in our study were not tested under win-shift versus win-stay conditions, our results demonstrate that these hummingbirds avoid revisiting emptied flowers over much longer time periods than a few seconds. The ability to remember emptied flowers over periods of several hours would be advantageous to these birds, because many flowers take more than four hours to replenish their nectar supply. As their performance on forced trials demonstrates, these birds are able to avoid emptied flowers by remembering the locations of specific flowers and not simply a route between them. In addition, we predict that if birds were tested over periods of greater than 4 or $5 \mathrm{~h}$, they might exhibit a stronger tendency to return to the flowers they had previously emptied. In other words, the preference for visiting previously unvisited flowers, like that seen in our data, might diminish or perhaps even reverse. If the latter were to occur, we would expect to see a preference for win-stay as opposed to win-shift.

Although the performance of the birds in our study is not as good as that shown by other species in radial maze analogues (see, e.g., Hilton \& Krebs, 1990), the hummingbirds performed better than chance, even with little training. Moreover, our experiment had two additional features that may have contributed to poorer performance by the hummingbirds: First, in many experiments done with a radial-arm maze (e.g., Moore \& Osadchuck, 1982; Wilkie, Spetch, \& Chew, 1981) the subjects have been allowed to feed from all reward sites without interruption, and the subjects generally complete the maze in about $10 \mathrm{~min}$. In our trials, the birds foraged from four sites and then experienced a retention interval that averaged almost $11 \mathrm{~min}$. Even if laboratory experiments involve retention intervals, the subjects do little during the retention interval that might interfere with their memory for the reward sites (e.g., Spetch and Edward's, 1956, pigeons waited in the dark; Balda and Kamil's, 1988, nutcrackers waited in a small home cage). It is very likely that our birds, on the other hand, engaged in other activities during the retention interval. These activities might have been as simple as watching for territorial intruders; or, if the interval was more than about $5 \mathrm{~min}$, they probably foraged elsewhere. The second feature that may 
have resulted in poorer memory performance is that our hummingbirds were not food deprived before performing the task; rather, they incorporated the array of artificial flowers as part of their foraging on real flowers in the area.

The combination, then, of an ordinarily laboratorybased technique and free-ranging birds has been successful and indicates that tests of animal memory need not be confined to the laboratory. What is perhaps lost in the degree of control is more than offset by both ethical and logistical benefits of uncaged animals and in offering "natural" memory problems. Tests of memory retention in "natural" environments, albeit in the laboratory, have shown that animals can perform well over very long time periods but that the same species' performance on rather more arbitrary tasks is poor in comparison (e.g., Balda \& Kamil, 1989; Healy \& Krebs, 1992a, 1992b; Olson, 1991). Our results do not necessarily indicate what the birds are capable of, but what the birds may actually do in the course of their normal behavior. Laboratory experiments permit us to investigate learning and memory performance under strictly controlled conditions, so, as a consequence, some caution should be exercised when one is interpreting results in evolutionary or ecological contexts. Field studies of learning and memory usage under natural conditions can thus serve as a valuable complement to laboratory studies by indicating whether or not the variables shown to be influential in the laboratory are truly effective in the animal's natural habitat.

\section{REFERENCES}

Armstrong, D. P., Gass, C. L., \& Sutherland, G. D. (1987). Should foragers remember where they've been? Explorations of a simulation model based on the behavior and energetics of territorial hummingbirds. In A. C. Kamil, J. R. Krebs, \& H. R. Pulliam (Eds.), Foraging behavior (pp. 563-586). New York: Plenum.

BALDA, R. P., \& KamIL, A. C. (1988). The spatial memory of Clark's nutcrackers (Nucifraga columbiana) in an analogue of the radial arm maze. Animal Learning \& Behavior, 16, 116-122.

BALDA, R. P., \& KAMIL, A. C. (1989). A comparative study of cache recovery by three corvid species. Animal Behaviour, 38, 486-495.

BeatTY, W. W., \& Shavalia, D. A. (1980). Spatial memory in rats: Time course of working memory and effect of anesthetics. Behavioral \& Neural Biology, 28, 454-462.

Bond, A. B., CoOK, R. G., \& LAMB, M. R. (1981). Spatial memory and the performance of rats and pigeons in the radial-arm maze. Animal Learning \& Behavior, 9, 575-580.
Cole, S., Hainsworth, F. R., Kamil, A. C., Mercier, T., \& Wolf, L. L. (1982). Spatial learning as an adaptation in hummingbirds. Science, 217, 655-657.

Davies, N. B., \& Houston, A. I. (1981). Owners and satellites: The economics of territory defence in the pied wagtail, Motacilla alba. Journal of Animal Ecology, 50, 157-180.

Feinsinger, P. (1978). Ecological interactions between plants and hummingbirds in a successional tropical community. Ecological Monographs, 48, 269-287.

Gass, C. L., ANGEhr, G., \& CenTA, J. (1976). Regulation of food supply by feeding territoriality in the rufous hummingbird. Canadian Journal of Zoology, 54, 2046-2054.

GilL, F. B., \& WolF, L. L. (1977). Non random foraging by sunbirds in a patchy environment. Ecology, 58, 1284-1296.

HEALY, S. D., \& KREBS, J. R. (1992a). Comparing spatial memory in two species of tit: Recalling a single positive location. Animal Learning \& Behavior, 20, 121-126.

Healy, S. D., \& KreBS, J. R. (1992b). Delayed-matching-to-sample by marsh tits and great tits. Quarterly Journal of Experimental Psychology, 45B, 33-47.

Hilton, S. C., \& KREBS, J. R. (1990). Spatial memory of four species of Parus: Performance in an open-field analogue of a radial maze. Quarterly Journal of Experimental Psychology, 42B, 345-368.

KAMIL, A. C. (1978). Systematic foraging by a nectar-feeding bird, the Amakihi (Loxops virens). Journal of Comparative Physiology \& Psychology, 92, 388-396.

Kodric-Brown, A., \& Brown, J. H. (1978). Influence of economics, interspecific competition, and sexual dimorphism on territoriality of migrant rufous hummingbirds. Ecology, 59, 285-296.

MOORE, F. R., \& OsADCHUCK, T. E. (1982). Spatial memory in a passerine migrant. in F. Papi \& H. G. Wallraff (Eds.), Avian navigation (pp. 319-325). New York: Springer-Verlag.

Olson, D. (1991). Spatial memory in Clark's nutcrackers, scrub jays and pigeons. Journal of Experimental Psychology: Animal Behavior Processes, 17, 363-376.

Olton, D. S., \& SAMUELson, R. J. (1976). Remembrance of places passed: Spatial memory in rats. Journal of Experimental Psychology: Animal Behavior Processes, 2, 97-116.

Paton, D. C., \& Carpenter, F. L. (1984). Peripheral foraging by territorial rufous hummingbirds: Defence by exploitation. Ecology, 65, 1808-1819.

Roberts, W. A., \& VAN Veldhuizen, N. (1985). Spatial memory in pigeons on the radial maze. Journal of Experimental Psychology: Animal Behavior Processes, 11, 241-260.

SPETCH, M. L., \& EDWARDS, C. A. (1986). Spatial memory in pigeons (Columba livia) in an open-field feeding environment. Journal of Comparative Psychology, 100, 266-278.

WILkIE, D. M., Spetch, M. L., \& Chew, L. (1981). The ring dove's short-term memory capacity for spatial information. Animal Behaviour, 29, 639-641.

(Manuscript received June 10, 1993; revision accepted for publication May 10, 1994.) 